\title{
Potential and Drawbacks of Raman (Micro)Spectrometry for the Understanding of Iron and Steel Corrosion
}

\author{
Philippe Colomban \\ LADIR, CNRS - Université Pierre-et-Marie-Curie \\ France
}

\section{Introduction}

Raman scattering theory and first observation date back to the first decades of the 20 Century but the technique did not generalise until the 70s, with the development of lasers technology. Two major breakthroughs occured in the $80 \mathrm{~s}$ with the replacement of monochannel PM detectors by multichannel CCDs (Delhaye et al., 1996) and in the 90s with the rejection of Rayleigh elastic scattering by photonic crystals (Notch filter) or multilayer coatings (Edge filter) rather than monochromator(s). These latter technological changes improved the sensitivity by many orders of magnitude, which allowed either cutting the counting time (allowing mapping or real time monitoring) or reducing the illumination power (thus allowing for the analysis of black compounds). The latest developments concern the miniaturization of solid laser sources and the replacement of electronic boxes controlling the CCD detector by softwares uploaded on a common laptop, leading to portable Raman instruments. All these developments and the increase of the Raman instrument production lowered the price and made the technique more and more available, even for in-line/at-line/on-line control.

Among the many interactions of light with matter, Raman scattering is particularly well suited to the multiscale analysis of ill-organized heterogeneous solids as the corrosion films (Gouadec \& Colomban, 2007a; ibidem, 2007b). The Raman probe being for interatomic bonds themselves, the technique offers a "bottom-up" approach to study nanomaterials and amorphous compounds which best works in the case of imperfect crystals with strong covalent bonds (Fig. 1) such as those typically produced by metal corrosion.

Raman signal results from the interaction of a monochromatic coherent light (laser beam) with electronic and vibrational levels of atomic bonds (Long, 1977; Lewis \& Edwards, 2001; Gouadec \& Colomban, 2007 for a more complete theoretical description). The interaction with the electronic levels is often described as virtual; this is true for non-coloured samples or nonabsorbent for the excitation laser line, but wrong for absorbent materials, leading to (pre)resonance Raman features. Consequently, peak intensity will depend on the exciting wavelength and 2nd order Raman features could be present (harmonics, combinations). Theory predicts both elastic (so called Rayleigh scattering) and inelastic (namely Raman) contributions in the scattered electric field. The latter occurs only if vibrations change bond polarizability, which is a second rank tensor containing the crystal symmetry. Raman scattering is 
complementary to infrared absorption with the advantage of much narrower peaks: the Raman peak shape is thus very informative because the Raman probe is very local. On the other hand, the IR spectroscopy probes, the instantaneous dipole moments which are subjects of much longer distance interactions. Consequently, IR bands are often very broad.

Raman spectroscopists in general refer the vibrational modes, the phonons, by i) their wavenumber $\bar{v}=v_{\text {vib }} / c$ ( $c$ the light speed, $\bar{v}$ in $\mathrm{cm}^{-1}$ unit, here after and usually noted $v$ ) and expressed it in $\mathrm{cm}^{-1}$, however energy $(\mathrm{meV})$, wavelength $(\mathrm{nm})$ are frequency $(\mathrm{THz})$ units can also be used and ii) their symmetry (total symmetric modes are the strongest ones).

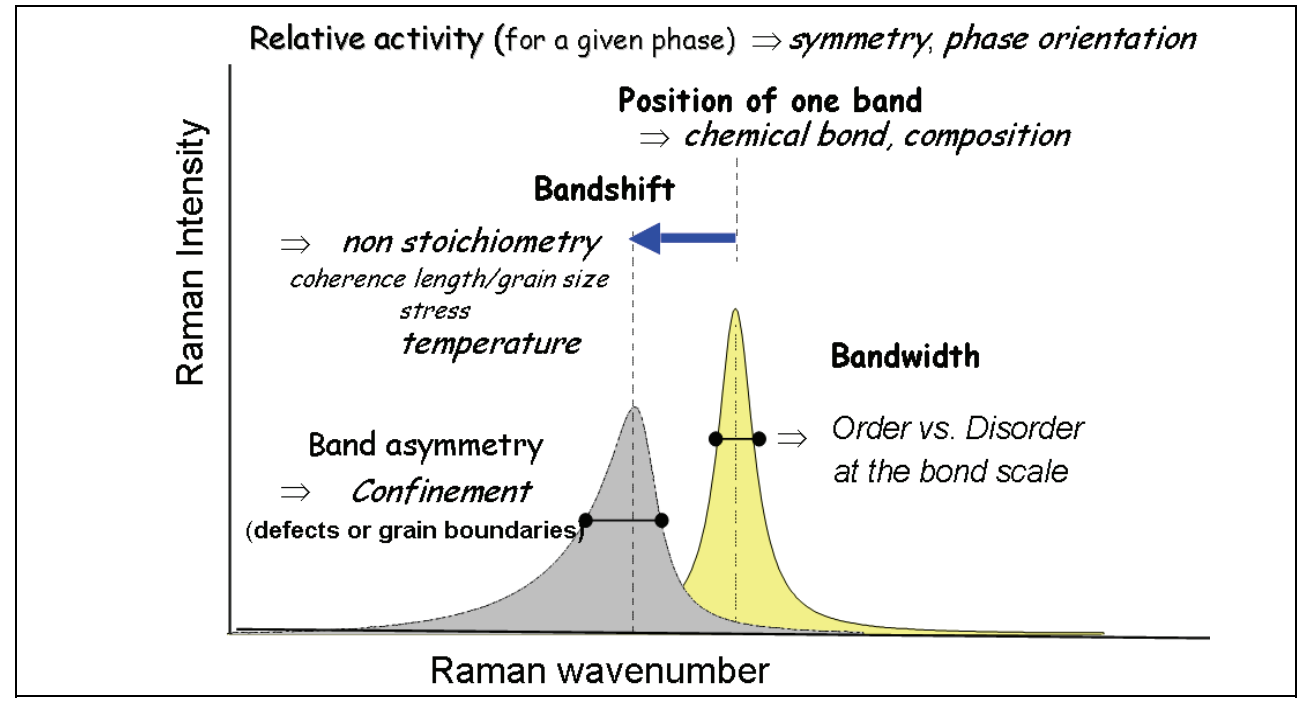

Fig. 1. The basics of the information to be extracted from a Raman spectrum (after Gouadec et al., 2010).

The polarization of a sample illuminated with light (electric field $\overrightarrow{\mathrm{E}}_{0}$; frequency $v_{1}$ ) has the following form:

$$
\overrightarrow{\mathrm{P}}=\overline{\mathrm{a}} \times \overrightarrow{\mathrm{E}}_{0} \cos \left(2 \pi v_{1} \mathrm{t}\right)
$$

In Eq. (1), $\overline{\bar{\alpha}}$ represents the polarizability tensor, which depends on matter vibrations (the oscillations of atoms and molecules around their equilibrium positions). The polarization can be expressed as a function of the atomic displacement (normal coordinates) using a Taylor approximation, thus predicting elastic scattering $\left(\mathrm{v}=\mathrm{v}_{\mathrm{l}}\right.$, the exciting laser wavenumber) and inelastic $\left(\mathrm{v}=\mathrm{v}_{\mathrm{l}} \pm \mathrm{v}_{\mathrm{vib}}\right)$ scattering by atomic vibrations. The former is called Rayleigh scattering and the latter, which occurs only if vibrations change polarizability $\left(\partial \alpha_{\mathrm{ij}} / \partial \mathrm{Q} \neq 0\right)$, is Raman scattering. Other terms correspond to Hyper and higher orders Raman scattering (Long, 1977: Gouadec \& Colomban, 2007a).

The signal intensity is predicted with the following formula:

$$
\mathrm{I}_{\text {Raman }} \propto \mathrm{I}_{\text {laser }} \overline{\mathrm{v}}_{\text {laser }}\left|\mathrm{e}_{0} \overline{\overline{\mathrm{a}}} \mathrm{e}_{\mathrm{s}}\right|^{2} \mathrm{~d} \Omega
$$


In Eq. (2), $e_{o}$ and $e_{s}$ are unit vectors indicating the laser polarization and direction of observation, respectively, whereas $\mathrm{d} \Omega$ represents the solid angle of light collection, at a maximum when high magnification, high aperture number microscope objectives are used. Classical electromagnetic theory predicts Raman peaks should have a Lorentzian shape (Long, 1977; Lewis \& Edwards, 2001; Gouadec \& Colomban, 2007a). Isotropic disorder leads to a distribution of Lorentzian usually described by a Gaussian shape. Actually more complex shapes (e.g. asymmetric ones in the case of anisotropic disorder, Fig. 1) occur and complex laws should be used (Havel et al. , 2004; Gouadec \& Colomban, 2007a; Havel et al., 2007) to describe the Raman signature of some nanophased materials or when defects break the phonon propagation (Havel et al., 2007; Chi et al., 2011).

The scattering intensity varies by orders of magnitude depending on the bond polarisability (the more covalent the bonds, the higher the number of electrons involved and the higher the Raman peak intensity), the crystal symmetry and the exciting wavelength. As polarizability ( $\overline{\bar{\alpha}}$ second rank tensor) changes drastically from one bond to another, Raman intensity may not be used to measure the relative amounts of different phases without preliminary calibration. Consequently, minor phases or even traces could have a stronger Raman signature than some major phases. The preferential orientation of certain phases, common for surface grown phases enhances some peaks and calibration cannot be efficient. The absorption of the laser light by coloured phases can be very high and thus the penetration depth can be less than a few tenths of nm (Gouadec \& Colomban, 2001; Havel \& Colomban, 2006). Furthermore light absorption may involve strong local heating and thus phase transformation towards more stable ones, crystallization of amorphous ones or oxidation (de Faria et al., 1997; de Faria \& Lopez, 2007; Cvejic et al., 2006). Raman analysis appears very sensitive to answer some questions on a given material whereas can be nether useless to study some others. Mapping (see further) and quantitative analysis should be then performed with caution.

Since Raman instruments were made available in the 70s, attempts to characterize the corrosion products of iron-based artefacts were performed. Most of studies concerned pure iron or low carbon content alloys but reference spectra are now available for large majority of the most common corrosion products: haematite, (Beattie \& Gilson, 1970), magnetite (Morke et al., 1980)), lepidocrocite (Thibeau et al. 1978). First series of corrosion studies flourish during the 80's (Farrow, 1980; Farrow \& Nagelberg, 1980; Keiser et al., 1982; HugotLe Goff \& Pallotta, 1985; Naouer et al. 1985; Ohtsuka et al., 1986; Boucherit et al. 1989, Dünnwald \& Otto, 1989). Then, high sensitivity instruments made it possible to study black and low crystallinity/amorphous films that were easily transformed into the stable ones by laser heating (Gouadec et al. 2001; Mazetti \& Thistlethwaite, 2002; Cvejic et al., 2006: Gouadec \& Colomban, 2007; Gouadec et al., 2010). More recently, mapping allowed getting a semi-quantitative global view (Neff et al., 2005; Neff et al., 2006 ; Monnier et al., 2010). A great effort was made to obtain reference phases and their signature, especially by controlled electrochemically synthesis (Savoy et al., 2001; Sinard et al., 2001; Joinet et al., 2002; Legrand et al. 2003, Refait et al. 2003, Poupard et al. 2006, Pineau et al. 2008; Dubois et al. 2008).

In this chapter we address the advantages of Raman spectroscopy and mapping, with particular attention to the intrinsic experimental and conceptual drawbacks of the methods as well as possible ways to overcome them. 


\section{Phases issued from metal corrosion and their Raman signature}

\subsection{Phase and structure relationship}

The corrosion of metal results from the reaction with anions and the formation of new bonds at the surface. The simplest case is the oxidation (formation of $\mathrm{Fe}^{\mathrm{II} / \mathrm{III}} \mathrm{O}$ bonds) but hydroxylation $\left(\mathrm{Fe} \mathrm{II}^{\mathrm{IIII}}-\mathrm{OH}\right)$, carbonatation $\left(\mathrm{Fe}-\mathrm{CO}_{3}\right)$, phosphatation $\left(\mathrm{Fe}-\mathrm{PO}_{4}\right)$, and sulfatation $\left(\mathrm{Fe}-\mathrm{SO}_{4}\right)$, etc... can occur by uncontrolled or controlled reactions with the moieties present in the vicinity of the metal surface. Ionic diffusion is driven by chemical and electrochemical gradients, which depends on the material structure. The ionic (mostly protonic) (Colomban, 1992) and electronic conductivity as well as the presence of liquid electrolytes such as water are prominent parameters. We will discuss the Raman signature of iron-based compounds but all the phases (oxides, hydroxides, carbonates, sulphates, etc.) of any element used in the alloy must be considered because corrosion may promote their formation and trace phases may have a signature sufficiently strong to be detected.

The densest phase is wustite because of its high $\mathrm{Fe} / \mathrm{O}$ ratio $\left(\mathrm{Fe} \mathrm{II}^{\mathrm{O}}\right.$, space group $\mathrm{Fm} 3 \mathrm{~m}$, density: $\sim 6$, black). Two other dense phases are built with two available ways of oxygen

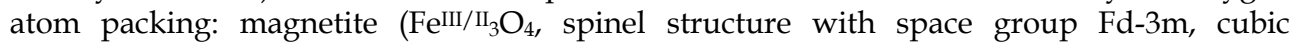
ABCABC packing, density 5.18, black) and haematite $\left(\mathrm{Fe}^{\mathrm{III}} \mathrm{O}_{3}\right.$, corundum structure with space group R-3c , hexagonal ABAB packing, density 5.23, dark red, Froment et al., 2008). When oxygen vacancies are formed - that decreases the density - the oxygen layer packing is preserved but some protonation may occurs: i) maghemite $\left(\gamma \mathrm{Fe}_{2} \mathrm{O}_{3}\right.$, space group $\mathrm{P}_{3} 32$ preserves the cubic spinel structure but its density lowers to 4.87 , brown), ii) goethite ( $\alpha$ FeOOH, space group $2 / \mathrm{m} 2 / \mathrm{m} 2 / \mathrm{m}$, density : 4.3 to 3.3 , ochre to black ) and lepidocrocite ( $\gamma \mathrm{FeOOH}, \mathrm{Cmcm}$, density : 4, dark red) ; these phases retain the initial framework made of oxygen atom layers but the structure becomes more open due to oxygen defects. Furthermore, some oxygen atoms may be replaced by $\mathrm{Cl}$ ones (akaganeite $\beta \mathrm{FeOOH}$, density : 3.8 to 3.6, orange), especially at the phase surface. Other disordered phases are observed : ferroxyhyte $(\delta \mathrm{Fe}$ mixed ABA ACA packing, density : 3.8, brown), hydroxychlorides, $\beta \mathrm{Fe}^{\mathrm{II}_{2}}(\mathrm{OH})_{3} \mathrm{Cl}$ or the socalled "green rust" $\left(\mathrm{Fe}_{(1-\mathrm{II})} \mathrm{Fe}^{\mathrm{III}} \mathrm{x}(\mathrm{OH})_{2} \mathrm{Cl}_{\mathrm{x}}\left(\mathrm{SO}_{4}\right)_{\mathrm{z}}, \mathrm{nH}_{2} \mathrm{O}\right.$, AABBCC packing, a variant of the $\mathrm{ABC}$ cubic packing, green). White rust consists in the iron lamellar hydroxides (main phase: $\beta \mathrm{Fe}^{\mathrm{II}}(\mathrm{OH})_{2}, \mathrm{P}-3 \mathrm{~m} 1, \mathrm{ABAB}$ compact packing, white). Carbonates (siderite, $\mathrm{Fe}^{\mathrm{III}} \mathrm{CO}_{3}$, density $\sim 3.9 ; \mathrm{Fe}_{2}\left(\mathrm{CO}_{3}\right)(\mathrm{OH})_{2}$, and some other mixed frameworks) may also form. Sulfates ( $\left.\mathrm{Fe}^{\mathrm{IIISO}} \mathrm{SO}_{4}\right)$ result from sulphuric acid treatment in the finishing of steel before coating or plating.

Galvanized steel sheets received $\mathrm{ZnFe}$ or more complex (ZnNiMn, etc...) coatings that enlarge the variety of phases to be formed (Bernard et al., 1993; Marchebois et al., 2002a; ibidem, 2002b; Tomandl et al., 2004; Yadav et al., 2004; Hernandez et al., 2006; Refait et al., 2007; Colomban et al., 2008; Dubois et al., 2008) : smithsonite $\mathrm{ZnCO}_{3}, \mathrm{Zn}(\mathrm{OH})_{2}$ and complex phases like hydrozincite $\mathrm{Zn}_{5}(\mathrm{OH})_{6}\left(\mathrm{CO}_{3}\right)_{2}$ ("white corrosion"), $\mathrm{ZnCl}_{2}(\mathrm{OH})_{4} \mathrm{SO}_{4}, 5 \mathrm{H}_{2} \mathrm{O}$, phosphates like $\mathrm{Zn}_{3}\left(\mathrm{PO}_{4}\right)_{2}, \mathrm{H}_{2} \mathrm{O}$, $\mathrm{ZnS}$ ("black corrosion").

In the same way, water and/or high temperature resistant steels such as $\mathrm{Ni}$ and $\mathrm{Cr}$-rich and the corresponding oxides/hydroxides are formed : $\alpha \mathrm{CrOOH}, \mathrm{Cr}_{2} \mathrm{O}_{3}, \mathrm{NiO}$, spinels, ... (Beatie \& Gilson, 1970; Bernard et al., 1993; Zuo et al., 1996; Delichère et al., 1997; Colomban et al., 1999; Maslar et al., 2001). Reference spectra of common phases can be also found in review books (see e.g. Karr Jr, 1975; Nakamoto, 1997) and the data on parent compounds are very useful for the identification of solid solutions and ill-crystallized compounds (Delichère et al., 1988; Desilvestro et al., 1988; Colomban et al., 1999). Table 1 lists the most frequent corrosion products and their characteristic Raman fingerprints. 


\begin{tabular}{|c|c|c|c|}
\hline Compound & Formula/structure & $\begin{array}{l}\text { Characteristic } \\
\text { Wavenumber }^{+}\end{array}$ & Remarks \\
\hline Wustite & $\mathrm{FeO}$ & 655 & \\
\hline Haematite & $\mathrm{Fe}_{2} \mathrm{O}_{3} /$ Corrundum & $\sim 1320,290,220$ & \\
\hline Magnetite & $\mathrm{Fe}_{3} \mathrm{O}_{4} /$ spinel & 670 & $\begin{array}{l}\text { Easily } \\
\text { transforms into } \\
\text { haematite under } \\
\text { laser beam }\end{array}$ \\
\hline Maghemite & $\gamma \mathrm{Fe}_{2} \mathrm{O}_{3 x} \mathrm{H}_{\varepsilon} /$ spinel & $670-720, \sim 1400$ & idem \\
\hline Ferrihydrite & $\mathrm{Fe}_{5} \mathrm{HO}_{8}, 9 \mathrm{H}_{2} \mathrm{O}$ & 710, 1380 & \\
\hline Goethite & $\alpha \mathrm{FeOOH}$ & 390 & \\
\hline Lepidocrocite & $\gamma \mathrm{FeOOH}$ & 250,1300 & \\
\hline Akaganeite & $\beta \mathrm{FeOOH}(\mathrm{Cl})$ & $310,390,720$ & \\
\hline Ferroxyhyte & $\delta \mathrm{FeOH}$ & $680, \sim 1350$ & idem \\
\hline Hydroxychloride & $\beta \mathrm{Fe}_{2}(\mathrm{OH})_{3} \mathrm{Cl}$ & 160,423 & \\
\hline Green rust & & $430-510$ & \\
\hline Iron chloride & $\mathrm{FeCl}_{2}$ & 610 & \\
\hline Zinc chloride & $\mathrm{ZnCl}_{2}$ & 80,248 & \\
\hline Zinc oxide & $\mathrm{ZnO}$ & $100,540-580$ & \\
\hline Zinc hydroxide & $\mathrm{Zn}(\mathrm{OH})_{2}$ & 470 & \\
\hline Zinc carbonates & $\mathrm{ZnCO}_{3}$ & 1095,370 & \\
\hline White rust & $3 \mathrm{Zn}(\mathrm{OH})_{2} 2 \mathrm{ZnCO}_{3}$ & 1050,385 & \\
\hline " & $\begin{array}{l}4 \mathrm{Zn}(\mathrm{OH})_{2} \mathrm{ZnCl}_{2}(\mathrm{OH})_{4} \\
\mathrm{H}_{2} \mathrm{O}\end{array}$ & $910,3455-3486$ & \\
\hline " & $\mathrm{Zn}(\mathrm{OH})_{4} \mathrm{Cl}_{2} \mathrm{SO}_{4} 5 \mathrm{H}_{2} \mathrm{O}$ & 955, 208, 292 & \\
\hline " & $\begin{array}{l}\mathrm{ZnSO}_{4} 3 \mathrm{Zn}(\mathrm{OH})_{2} \\
3 \mathrm{H}_{2} \mathrm{O}\end{array}$ & $961,1007,463$ & \\
\hline Zinc phosphate & $\mathrm{ZnPO}_{4}$ & 996 & \\
\hline " & $\mathrm{Zn}_{3}\left(\mathrm{PO}_{4}\right)_{2} \mathrm{H}_{2} \mathrm{O}$ & 1055,1150 & \\
\hline Manganese oxide & $\mathrm{MnO}_{2}$ & $\sim 600$ & \\
\hline Nickel oxide & $\mathrm{NiO}$ & $\sim 510$ & \\
\hline Chromium oxide & $\mathrm{Cr}_{2} \mathrm{O}_{3}$ & $351,551,609$ & \\
\hline $\begin{array}{l}\text { Chromium } \\
\text { hydroxide }\end{array}$ & $\mathrm{CrOOH}\left(\mathrm{Cr}_{2} \mathrm{O}_{3}, \mathrm{nH}_{2} \mathrm{O}\right)$ & 485 & \\
\hline Mackinawite & $\mathrm{FeS}$ & $\sim 280-300$ & \\
\hline Greigite & $\mathrm{Fe}_{3} \mathrm{~S}_{4}$ & $\sim 350-360$ & \\
\hline
\end{tabular}

Table 1. Raman fingerprint of main corrosion products.

\subsection{Understanding Raman signature}

If the analytic approach is useful (identification and quantification of the phases formed by corrosion), a more comprehensive understanding of the phase structures and relationship is necessary for a comprehension of the reaction scheme and the prospect of regulating them. The recording of the Raman signatures will depend on the phase colour - i.e. their electronic band structure - that determines the light penetration and the intensity of the scattered 
signal as well as on the phase structure : the higher the symmetry, the lower number of Raman peaks (Lewis \& Edwards, 2001; Gouadec \& Colomban, 2007a).

Fig. 2 shows the Raman signature of the main phases encountered in the corrosion layers. Typical intensity ratios in comparable recording conditions are:

Lepidocrocite (1) > wustite, haematite, goethite, hydroxychloride, ferrihydrites, ferroxyhite $(\sim 1 / 3)>$ akaganeite $(\sim 1 / 4)>>$ magnetite, maghemite $(\sim 1 / 10)$.
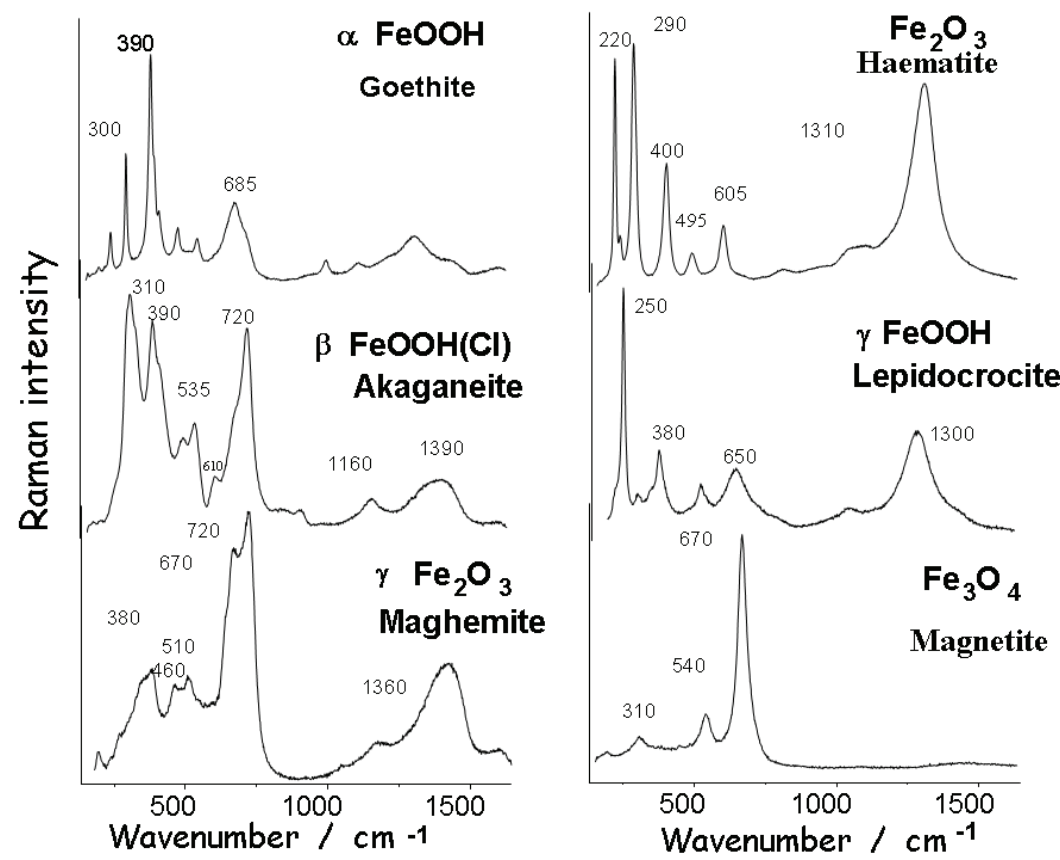

Fig. 2. Raman signature of the main (crystalline) iron oxi(hydroxy)des observed in corrosion films (after Colomban et al., 2008).

It is thus clear that the analysis of a mixture will strongly lower the contribution of the latter phases.

The Raman signature of any compound that structure is built with one or many strong covalent-bonded vibrational units, can be separated in four groups (Gouadec \& Colomban, 2007a):

i. (symmetric) stretching modes, for instance $\mathrm{Fe} \mathrm{II}_{-} \mathrm{O}$ and/or $\mathrm{Fe}^{\mathrm{III}}-\mathrm{O}$ modes peaking in the $400-700 \mathrm{~cm}^{-1}$ region for oxides, 300-600 $\mathrm{cm}^{-1}$ for chlorides , 200-400 $\mathrm{cm}^{-1}$ for sulphides. In symmetric modes, the strongest ones, only oxygen atoms move and thus the peak wavenumber mainly depends on the Fe-O distance (Vucinic-Vasic et al., 2006). These modes are very sensitive to oxygen vacancies that broaden the peaks.

ii. bending modes peak at lower energy, namely $400-500 \mathrm{~cm}^{-1}$ range for oxides or less for chlorides, sulphides,... They are very sensitive to the short range disorder in the first neighbouring shell (1-5 nm around the chemical bond) and their broadness can be very informative on the short-range (dis)order. Because the mean symmetry often brokes the symmetry of the vibrational units, many components are frequently observed. 
iii. librational (orientational oscillations, $150-400 \mathrm{~cm}^{-1}$ range) and lattice modes $\left(<200 \mathrm{~cm}^{-1}\right)$. Librational modes are very sensitive to the short range disorder of the vibrational entities (e.g. $\mathrm{FeO}_{4}$ tetraedron); lattice modes reflect the long range crystalline order, like $\mathrm{X}$-ray diffraction, and strongly depend on atom mass $(\sqrt{ } \mathrm{M})$.

iv. additional features (combination, harmonics,...) consisting bands between 1000 and $1500 \mathrm{~cm}^{-1}$ : their origin lies in the interaction between electronic (and magnetic, see e.g. (Morke et al., 1980)) levels and the light because the laser beam wavelength interacts with the electronic levels. The high intensity of these bands facilitates the phase identification. On the other hand the high light-matter coupling leads to a strong heating under the laser spot: temperatures close to $500^{\circ} \mathrm{C}$ can be easily achieved. The temperature does not depend on the laser power and objective magnification only but also on the heat dissipation (Gouadec et al., 2001): the dissipation is often better for small aggregates but matrix effects are important. Measurements at low temperature (liquid $\mathrm{N}_{2}$ ) or in water should be preferred .

Taking into account the above rules it is obvious that the narrow low wavenumber peaks of lepidocrocite, hematite, goethite and some hydroychlorides are characteristic of crystalline phases. The strong intensity of their lattice modes is typical for layered materials. Replacing atoms by heavier ones $(\mathrm{O} / \mathrm{Cl}$ for instance in hydroxychlorides) shifts the lattice modes toward lower wavenumbers and broadens the different components. The relationships between haematite, lepidocrocite, goethite and akaganeite on one side (both phases having $\mathrm{AB}$ derived packing, Fig. 2), and on the other hand magnetite, maghemite, ferrihydrites (ABC packing) are obvious (Colomban et al., 2008). Partial substitution modifies the bandwidth (Cvejic et al., 2006).

Detection of "pure" hydroxides (white rust), carbonates and sulphates (black rust) is very easy because of the narrowness of their stretching mode (1020-1100 $\mathrm{cm}^{-1}$ range) and because reference spectra are well documented (Karr Jr, 1975; Nakamoto, 1997)). Furthermore, high power of illumination can be used for non-coloured phases. Actually, in most of the practical cases, corrosion films are made of complex intergrowths at the nanoscale, giving rise to mixed oxyhydroxycarbonates/sulfates/etc. with complex Raman signatures because of the solid solutions formation, intimate mixtures of ill-crystallised phase with a very small grain size. Synthesis and characterisation of reference compounds are complex (handling in $\mathrm{CO}_{2^{-}}$and/or water-free media, redox control...). Fig. 4 shows spectra recorded on galvanized steel sheets corroded in real conditions. In most of the cases fluorescence, a phenomenon in competition with Raman scattering but more efficient, gives rise to a strong background for real samples (galvanised steel coupons have been cut from vehicles that have been in circulation for years in severe weather conditions). The fluorescence often due to microbiological activity can be eliminated by $\mathrm{H}_{2} \mathrm{O}_{2}$ or $\sim 500^{\circ} \mathrm{C}$ thermal treatment (furnace heating or laser cleaning). On the other hand, spectra free of fluorescence background are easier recorded on coupons accelerated corroded at the laboratory. Indeed, reagents are simpler and cleaner. However, the most stringent point is that formed phases are often different. It is clear that many improvements on the procedure to conduct accelerated tests, more representative for real corrosion have to be made.

For specific applications special coatings like Cr(Al)N, NiCrAlY (Colomban et al., 1999) or polyaniline films (Delichère et al., 2007; Bernard et al., 2002; Nguyen et al., 2004) are used. This requires special database.

Note that Raman analysis is possible through a layer, inorganic (enamel, ceramic matrix (Wu et al, (1997); Gouadec et al.(1998)) or organic one (paint, e.g. Colomban et al., 2008). Typically, good Raman signatures are obtained up to 20 to $40 \mu \mathrm{m}$ below the surface. 


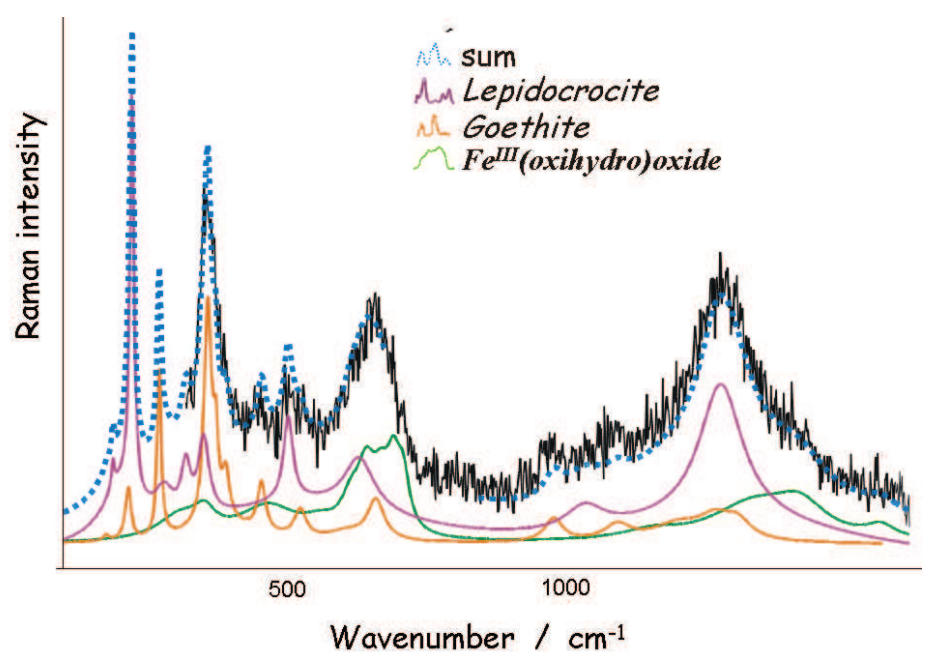

Fig. 3. Example of the decomposition of the Raman spectrum of a corroded film using the 3 signatures of pure reference phases. The appropriate program was then ran to adjust the data in all the mapped area with these combination spectra and to image the protective ability index in all the studied area (adapted from Gouadec et al., 2010). Note the very narrow $250 \mathrm{~cm}^{-1}$ peak characteristic of Lepidocrocite layer structure and the strong $2^{\text {nd }}$ order features at $\sim 1350-1400 \mathrm{~cm}^{-1}$ of spinel derived ill crystallized phases.

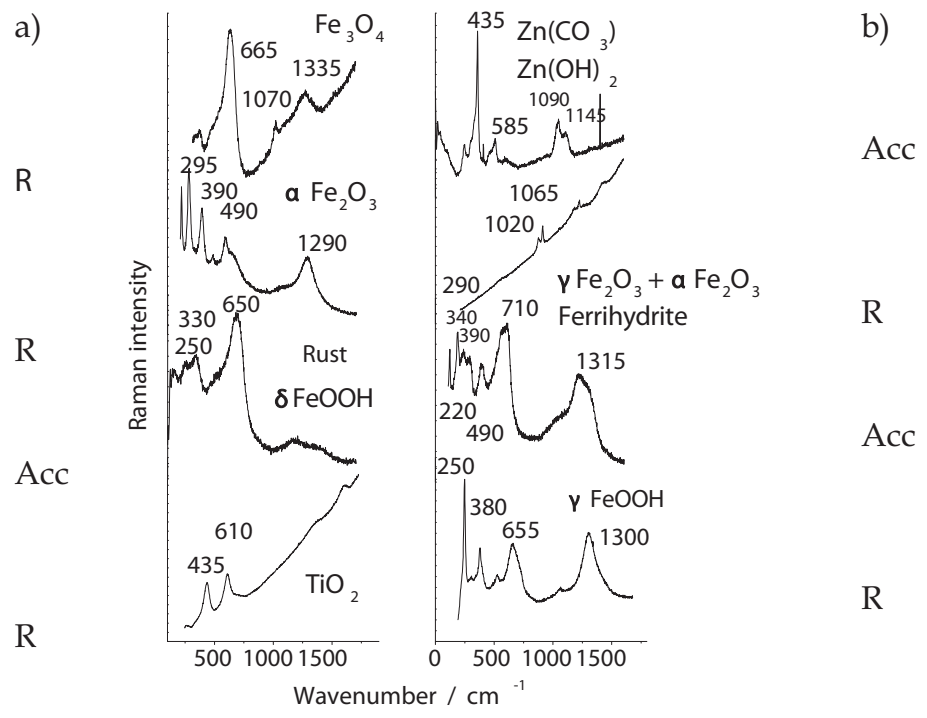

Fig. 4. Example of Raman signatures recorded in different spots of a corroded galvanized steel sheet with the sequences a) steel/Zn-based coating/phosphate coating/epoxy- $\mathrm{TiO}_{2}$ paint and b) steel/ZnFe coating/ZnNiMn coating/ epoxy- $\mathrm{TiO}_{2}$ paint; accelerated (Acc) or real (R) corrosion conditions (after Colomban et al., 2008). 


\subsection{Semiquantitative analysis and phase mapping}

Raman mapping is most valuable to point out subtle composition and structure modifications taking place from one place of a sample to another. The images are obtained by extracting pertinent parameters from the hyperspectral map, which is a collection of individual Raman spectra, each being associated with a given point on the sample surface (Turrell, 1996; Colomban, 2003).

The great advantage of the automatic mapping procedure is the achievement of a more representative view of the present phases. However, the visual selection of the spot to be analysed is very subjective and leads to neglect places where the optical focus view through the microscope objective looks poor (low contrast, roughness, ...).

Using the parameter(s) extracted from each spectrum (peak intensity, wavenumber shift but also grain size, defect concentration, etc.), it is possible to build a map of the investigated area the so-called smart image (Colomban, 2003). The following requirements are mandatory to record and exploit Raman mapping (Gouadec et al., 2010):

i. the analysed area must be horizontal and the roughness smaller than the vertical height of the laser spot (typically, $10 \mu \mathrm{m}$ for $\mathrm{x} 100, \sim 50 \mu \mathrm{m}$ for $\mathrm{x} 50$ magnification objective,... )

ii. the horizontal resolution, i.e. the laser spot diameter ( less than $\sim 1 \mu \mathrm{m}$ for $x 200, \sim 5 \mu \mathrm{m}$ for $\mathrm{x} 100, \sim 10 \mu \mathrm{m}$ for $\mathrm{x} 50$ magnification objectives) combined to the stage step $(\sim 0.1 \mu \mathrm{m}$ or more) must be compatible with the material/phase/grain size.

iii. the analyzed area must be chosen in order to be representative of the different topological features but limiting the number of spectrum to be collected and processed to built smart images (Colomban, 2003; Havel et al., 2004; Havel \& Colomban, 2006; Gouadec et al., 2010).

The image resolution will thus depend on the optical parts (objective and spectrometer), the laser beam quality (alignment, fundamental mode), the sample (parasite refractions at interfaces, roughness), Raman signature contrast, light absorption and penetration in the sample as well as the stage motion step, usually up to $0.1 \mu \mathrm{m} . .$.

The mapping has been used to understand the long term atmospheric and in soil corrosion taking advantage of the big thickness and large grain size of corrosion films (tenths of microns) present in heritage buildings (cathedrals, churches,...) and archaeological artefacts (Neff et al., 2005; ibidem, 2006; Monnier et al., 2010). Archaeological and Cultural Heritage artefacts are however considered as good analogues for the understanding and prediction of iron alloys corrosion behaviour in soil and in atmosphere, and hence to determinethe lifetime of over-containers used to protect the vitrified nuclear waste.

The Raman technique has also been used to compare the thinner ( $1-3 \mu \mathrm{m}$ thick) corrosion films obtained on automotive galvanized steels in accelerated corrosion tests, at the laboratory, and in real use (intense corrosion for used cars in severe mountain weathering conditions (temperature, water, salt (Colomban et al., 2008)). Raman analysis in the bottom of the pits formed by the corrosion is possible using long focus, large aperture high quality objectives.

\section{New challenges}

The current challenges are i) the development of data bases of complex mixed and nanosized phases, ii) the improvement of procedures/data treatment for two dimensional (2D) and three dimensional (3D) Raman mapping and iii) a better understanding of the $2^{\text {nd }}$ order Raman signature of coloured phases in order to obtained smart imaging of pertinent 
parameters, for instance to image the phase amount ratio that has been proposed to establish if the corrosion is passive or active (Kashima et al., 2000).

\subsection{Mixed oxides and oxyhydroxicarbonates}

Although the reference signatures of pure iron oxides are well established, those of the mixed compounds like spinels associating $\mathrm{Fe}, \mathrm{Mn}, \mathrm{Cr}, \mathrm{Ni}, \ldots$ atoms or of oxyhydroxycarbonates, hydrated or not, are very poorly documented (Colomban et al., 1999; Colomban et al. 2008; Cvejic et al., 2006). These phases may be unstable under the laser spot and may transform into more stable ones having different structure. Furthermore, for many films it is not established if the matter consists in a mixture, a phase or nanoparticles with another phase covering the grain surface. In many cases, because of the sample colour and its absorption of the laser light by electronic level, the interaction with electronic levels is anymore virtual and Raman (pre)resonance phenomenon is observed: the Raman intensity concentrates in some modes, a (small) wavenumber shift is observed and harmonic/combination second order peaks become visible. Note that in situ measurements under controlled electrochemical condition allow to record nice vibrational signature. However the representativity of these signatures is not straightforward because the real conditions are more complex what can promote the formation of other minor phases with stronger Raman cross section.

\subsection{Controlling the analysed area}

Most of the phases formed on the metal surface are coloured and hence absorb the light. Consequently the penetration depth of the light depends on the absorption coefficient. For dark phase the depth can be very limited and the information obtained from a mapping is perturbed: the analysed thickness will vary from spot to spot and correction is not possible. From a practical point of view, microscope objectives are usually characterized by the numerical aperture NA:

$$
\mathrm{NA}=\mathrm{n} \sin \left(\theta_{\text {back }}\right)
$$

In Eq (3), $\theta_{\text {back }}$ is the maximum collection angle for the backscattered light and $\mathrm{n}$ is the refractive index in the medium between the sample and the microscope lens (Fig. 5). The numerical aperture is a key parameter because it sets the resolution $\mathrm{R}$ of the microscope, defined as the shortest spacing for two points on a sample surface to be resolved with $\lambda$ wavelength observation (see references in Gouadec \& Colomban, 2007a; Gouadec et al., 2010):

$$
\mathrm{R}=0.6 \lambda / \mathrm{NA}
$$

Since the optics of ultraviolet light devices are expensive and not very efficient, the lasers offering violet $(\sim 450$ to $\sim 400 \mathrm{n})$ or deep violet $(\sim 365 \mathrm{~nm})$ excitations are preferred to obtain the best resolution. Actual laser beams are not perfectly parallel (this has been exaggerated in Fig. 5) and their focusing through a microscope lens gives an elongated volume called the focal domain or focal cylinder. The diameter $\phi(\mathrm{z})$ of the focal domain at $\mathrm{z}$ axial coordinate must be defined arbitrarily as the electric field obviously does not drop to zero for a definite $r$ distance away from the optical axis. The radial decrease of the electric field in a laser beam actually obeys a Gaussian law. Similarly to the lateral resolution, the in depth $\Delta z$ or axial $(\sim \phi(z))$ resolution of Raman spectroscopy can not be defined unambiguously. Indeed, the laser intensity does not drop to zero for a given $\mathrm{z}$ value and one has to choose an arbitrary 
threshold (the Raman efficiency shows order of magnitude variation that makes the choice very difficult !). $\Delta \mathrm{z}$ also depends on the generally unknown refractive index of the studied compound.

In confocal Raman microscopy set up, pinholes are placed in the microscope at intermediate image planes, resulting in a better in-depth discrimination power but a great increase of the counting times, 10 times and even more! In that case, the integrated intensity coming from a given plane perpendicular to the optical axis is no longer a constant but, rather, decreases by $50 \%$ between the focal plane $(\mathrm{z}=0)$ and $\Delta \mathrm{z}_{\text {confocal }}$ (the half width of the so-called point spread function). The use of confocal pinholes goes with a lateral resolution improvement of about one third but confocal microscopy interest mainly consists in the possibility to select sample layers axially. However, even with the best dry $\left(n=n_{a i r}=1, N A=0.95\right)$ or oil immersion $(\mathrm{n}=1.51, \mathrm{NA}=1.4)$ objectives, and in the most favourable case of a violet excitation (e.g. $\lambda \sim 407$ $\mathrm{nm}), \phi_{\text {spot }}$ will remain above $275 \mathrm{~nm}$ (Eq. (4)). The use of high quality (expansive) objectives is often more efficient that the confocal setting. Note bias polishing enlarge the topological resolution and micronic films can be easily analysed by the Raman technique (Gouadec et al., 2001).

Consequently the spatial repartition and relative proportion deduced from a Raman mapping may be interpreted with caution. The information can be however very useful to characterise the evolution of the corrosion film as a function of time, temperature, external parameters, etc.

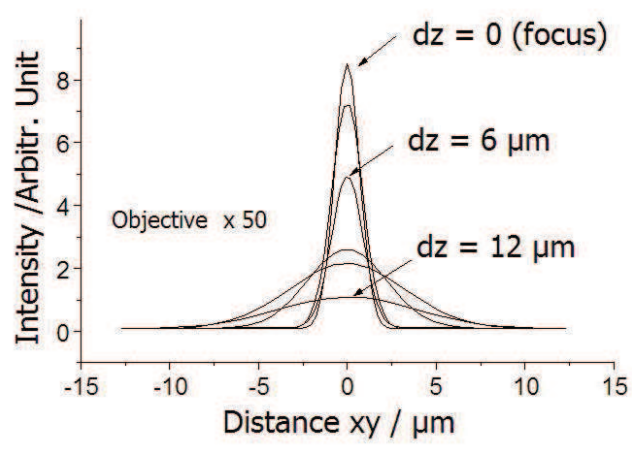

a)

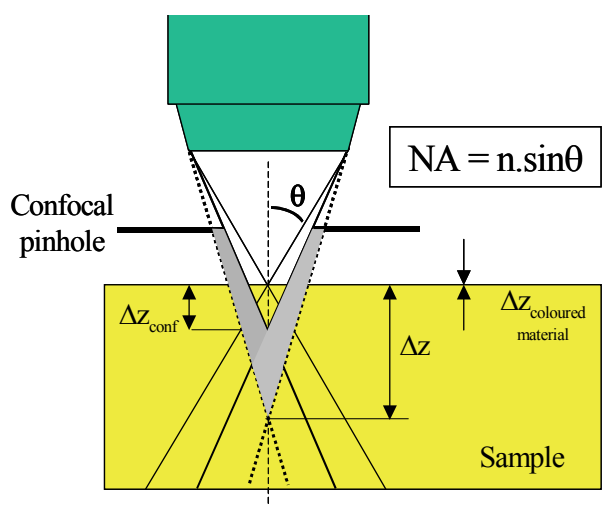

b)

Fig. 5. a) Intensity distribution of the illuminating laser spot as a function of the de-focus (after Colomban, 2003) ; b) schematic comparison of the focus in a non-absorbing medium with and without the use of a confocal pinhole in the optical system. Note the very limited penetration for coloured material (after Gouadec \& Colomban, 2007a).

\subsection{Understanding at the nanostructure scale}

The decrease of the grain size (D, see Fig. 6) makes that atoms at the particle surface or atoms having their chemical bonding perturbed by the vicinity of the surface ( $t$ : distance where the surface perturbs the structure and chemical bonds) become more important than the bulk atoms when the particle size drops below 30 to $5 \mathrm{~nm}$ as a function of elements and chemical bonding. Vacancy concentration is maximal close to the surface and adsorbed species can be present: hydroxylation, water, etc. 


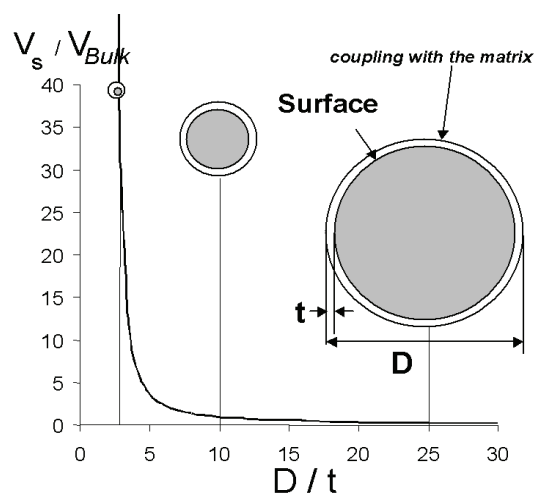

Fig. 6. Schematic of the relative contribution of skin/bulk matter for a particle as a function of its size: for a nanosized grain les than 1-10 $\mathrm{nm}$ in diameter the contribution of the surface atoms is very dominant (after Colomban, 2003).

The disorder modifies the Raman signature: symmetry exclusion can disappear leading to the activity of new components. The most prominent effect is the modification of the Raman peaks shapes. A reliable analysis of the Raman spectra requires the use of appropriate modelling to describe the band shape of the different spectral components (Gouaced \& Colomban, 2007a, Chi et al. 2010).

The use of simple Gaussian and Lorentzian band profiles is often preferred than the Voigt profile; many fitting modules misleadingly name Voigt profile the simple sum of one Lorentzian and one Gaussian, as both depend on three parameters rather than four. The exact position, intensity, width and lineshape of each band depend on many different parameters such as the actual chemistry (neighbouring inclusions, substitutions or vacancies), crystallinity, domain size, phase orientation and corresponding polarization effects or thermomechanical stress (anharmonic effects). In grains much larger than the wavelength, phonons propagate almost in the same way as in perfect "infinite" crystals. When the grain size falls below a few tens of nanometers, the Phonon Confinement Model (PCM) accounts for the phonons coherence length limitation by a weighed exploration of longitudinal optical dispersion curves (see Gouadec \& Colomban, 2007a nd 2007b and references herein). Below a certain size, the very notion of collective vibrations disappears and the Elastic Sphere Model (ESM) takes over, using first principle description of low wavenumber vibrations in a "free-standing", homogeneous (constant density) and elastic sphere (Fig. 7). In this scheme, the wavenumbers of the two most intense modes are inversely proportional to the grain size (Fig. 6).

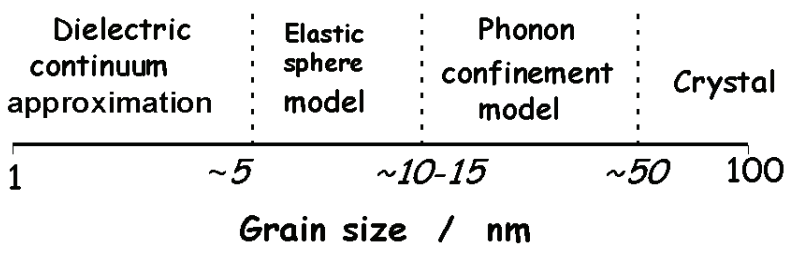

Fig. 7. Modelling spherical nanocrystals vibrations as a function of the grain size (after Gouadec \& Colomban, 2007) 


\subsection{Understanding the corrosion mechanisms and anticipating the evolution}

Although the phenomelogical description of corrosion has received attention since long time from the electrochemical and thermodynamical points of view, the understanding of the mechanisms from the solid state chemistry point of view remains very limited. For instance, many phases contain protons in different forms and data on proton conductivity are very scarce (Colomban, 1992). Vibrationnal spectroscopy can be very useful to document the structural changes associated to ion diffusion.

The action of micro-organisms was poorly documented from the spectroscopic point of view. Microbiollogically influenced corrosion is used since millennia to improve the plasticity of kaolin and clays by chemical modifications of silicates. This results from both, the direct action of microorganisms and the indirect one via the species generated by their metabolic activity. For iron-based materials, the phenomenon is induced in anoxic environments by sulphate-reducing bacteria (SRB), microorganisms that produced sulphide species. Thus, in media where sulphides are not naturally present, the observation of $\mathrm{Fe}^{\mathrm{II}}$ sulphides (all sulphides have their stronger peak at $\sim 250-350 \mathrm{~cm}^{-1}$ ) inside the rust layer may be a clear indication that SRB were active and play a role in the corrosion process. The heterogeneity of the biofilm that covers the metal surface can lead to a galvanic interaction between regions of microbial activity and the surface. This leads to locally accelerated corrosion pits (Videla \& Characklis, 1992; Marchal, 1999; Beech \& Sunner, 2004; Little \& Lee, 2007). When metal is associated with organic materials (some paints, films used for "conservation" treatments of archaeological artefacts, ...), consequence of microbiologically induced corrosion can be severe when contact with air: cracks occur due to the volume increase associated to iron oxidation and simultaneously sulphuric acid is produced. Raman study confirms that FeS (mackinawite) is very reactive towards oxygen (Remazeilles et al., 2010).

\section{Conclusion}

During decades Raman spectroscopy remains a useful technique for solid state physics and chemistry, giving valuable information about the structure and the reactivity of colourless single crystals. Then, clean polycrystalline, ill-crystallized samples can be analyzed. The high sensitivity of the modern instruments makes it possible to study any kind of samples if a palette of exciting laser wavelength is available to avoid detrimental pollution of the Raman information by strong fluorescence phenomenon. Very recently the potential of algorithmic methods to extract pertinent information from the spectra dominated by the fluorescence has been demonstrated (Widjaja et al., 2010) and the application of the BandTarget Entropy Minimization (BTEM) or similar techniques to the "poor" Raman signature of certain corrosion films appears very interesting.

\section{References}

Beattie, I.R. \& Gilson, T.R. (1970). The single-crystal Raman spectra of nearly opaque materials; Iron (III) oxide and chromium (III) oxide, J. Chemical Soc. A, 980-986.

Beech, I.B. \& Sunner, J. (2004). Biocorrosion: towards understanding interactions between biofilms and metals, Current Opinion Biotechnology, 15, [3], 181-186. 
Belo, M.D.; Walls, M.; Hakiki, N.E.; Corset, J.; Picquenard, E.; Sagon, G. \& Noel, D. (1998). Composition, structure and properties of the oxide films formed on the stainless steel 316L in a primary type PWR environment, Corrosion Science, 40, [2-3], 447-463.

Bernard, M.C.; Abourazzouk, D. \& Hugot-le-Goff, A. (1993a). The corrosion of Ni-Cr dental alloys studied by in-situ Raman spectroscopy - Role of Beryllium, Corrosion Science, 35, [1-4], 809-815.

Bernard, M.C., Hugot-Le Goff, A., Thierry, D.; Massinon, D. \& Philipps N. (1993b). Underpaint corrosion of Zinc-coated steel sheet studied by in-situ Raman spectroscopy, Corrosion Science, 35, [5-8], 1339-1345.

Bernard, M.C.; Duval, S.; Joiret, S.; Keddam, M.; Ropital, F. \& Takenouti, H. (2002). Analysis of corrosion products beneath an epoxy-amine varnish film, Progress Org. Coat., 45, [4], 399-404.

Boucherit, N.; Hugot-Le-Goff, A. \& Joiret, S. (1991). Raman studies of corrosion films grown on Fe and Fe-Mo in pitting conditions, Corrosion Sci., 32, [5-6], 497-507.

Boucherit, N., Hugot-Le-Goff A. \& Joiret S. (1992). PInfluence of Ni, Mo and Cr on pitting corrosion of steels studied by Raman scazttering, Corrosion, 48, [7], 569-579.

Bourdoiseau, J.-A.; Jeannin, M.; Remazeilles, C. ; Sabot, R. \& Refait, Ph. (2010). The transformation of mackinawite into greigite studied by Raman spectroscopy, J. Raman spectroscopy DOI: 10.1002/jrs.2729.

Chi, T.T.K.; Gouadec, G.; Colomban, Ph.; Wang, G.; Mazerolles, L.; Thanh, D.X. \& Liem, N.Q. (2010). Off Resonance Raman Spectroscopy of Stacking Disorder and Phase Transitions in Wurtzite Crystals Ground to Nanometric Dimensions: the Example of CdS, J. Raman Spectroscopy in press DOI:10.1002/jrs.2793.

Colomban Ph (1992), New Edition (2009) Proton Conductors, Cambridge University Press, Cambridge.

Colomban Ph (2003) Raman Analyses and "Smart Imaging" of Nanophases and Nanosized Materials, Spectroscopy Europe 15, 8-16.

Colomban, Ph.; Jullian, S.; Parlier, M. \& Monge-Cadet, P. (1999). Identification of the hightemperature impact/friction of aeroengine blades and cases by micro-Raman spectroscopy, Aerospace Science and Technology, 3, [7], 447-459.

Colomban, Ph.; Cherifi, S. \& Dexpert, G. (2008). Raman identification of corrosion products on automotive galvanized steel sheets, J. Raman Spectroscopy, 39, [7], 881-886.

Cook, D.C. (2005). Spectroscopic identification of protective and non-protective corrosion coatings on steel structures in marine environments, Corrosion Science, 47, [10], 2550-2570.

Cvejic Z.; Rakic S.; Kremenovic A.; Antic B.; Jovalekic C. \& Colomban Ph. (2006). Nanosize ferrites obtained by ball milling. Crystal structure, cation distribution, size-strain analysis and Raman investigations, Solid State Science, 8, [8], 908-915.

Delhaye, M.; Barbillat, J.; Aubard, J. et al. (1996) Chap 3: Instrumentation. in: Turrell G and Corset J (eds) Raman Microscopy. Developments and Applications. Academic Press, London.

Delichère, P.; Hugot-le-Goff, A.; Pallotta, C.; Thierry, D. \& Yu N. (1987). Raman spectroscopy for the study of passive abnd transpassive film on $\mathrm{Ni} / \mathrm{Mo}$ and $\mathrm{Fe} / \mathrm{Cr}$ alloys, Proc. Eurocorr'87, Karlsruhe, Germany, 6-10 April 1987. 
Delichère, P.; Hugot-le-Goff, A. \& Joiret, S. (1988). Study of thin corrosion films by in situ Raman spectroscopy combined with direct observation of nuclear reactions, Surface and Interface Analysis, 12, [1-12], 419-423.

Delichère, P.; Joiret, S. \& Hugot-le-Goff, A. (1988). Electrochromism in nickel oxide film, SPIE Vol 1016 Optical Material Technology for Energy Efficiency and Solar Energy Conversion VII, 165-169.

Desilvestro, J.; Corrigan, D.A. \& Weaver, M.J. (1988). Characterization of redox state of Nickel hydroxide film electrodes by in situ Surface Raman spectroscopy, J. Electrochemical Society, 135, [4], 885-892.

Dubois, F.; Mendibide, C. \& Pagnier, T. (2008). Raman mapping of corrosion products formed onto spring steels during salt spray experiments. A correlation between the scale composition and the corrosion resistance, Corrosion Science, 50, [12], 3401-3409.

Dünnwald, J. \& Otto, A. (1989). An investigation of phase transitions in rust layers using Raman Spectroscopy, Corrosion Science, 29, [9], 1167-1176.

Farrow, R.L. \& Nagelberg A.S. (1980). Raman spectroscopy of surface oxides at high temperature, Applied Physics Letters, 36, [12], 945-947.

Farrow, R.L.; Benner R.E.; Nagelberg A.S. \& Mattern P.L. (1980). Characterization of surface oxides by Raman spectroscopy, Thin Solid Films; 73, [2], 353-358.

de Faria, D.L.A.; Venâncio Silva, S. \& de Oliveira, M.T. (1997). Raman microspectroscopy of some iron oxides and oxyhydroxides, J. Raman Spectroscopy 28, [11], 873-878.

de Faria, D.L.A. \& Lopes F.N. (2007). Heated goethite and natural hematite: Can Raman spectroscopy be used to differentiate them?, Vibrational Spectroscopy 45, [2], 117-121.

Froment, F. ; Tournié, A. \& Colomban Ph. (2008). Raman identification of natural red to yellow pigments: ochre and iron-containing ores, J. Raman Spectroscopy 39, [5], 560568 .

Gouadec, G.; Karlin, S. \& Colomban, Ph. (1998). Raman extensometry study of NLM202 and Hi-Nicalon ${ }^{\circledR}$ SiC fibres, Composites, Part B 29, [3], 251-261

Gouadec, G.; Ph. Colomban, Ph. \& Bansal, N.P. (2001). Raman Study of Hi-Nicalon Fiber Reinforced Celsian Composites. Part I : Distribution and Nanostructure of Different Phases, J. Amer. Ceram. Soc. 84, [5], 1129-1135. Part II: Residual Stress In The Fibers, J. American Ceramic Society 84, [5], 1136-42.

Gouadec, G. \& Colomban, Ph. (2007a). Raman study of Nanomaterials : How spectra relate to disorder, particle size and mechanical properties, Progr. Cryst. Growth \& Charact. Mater., 53, [1], 1-56.

Gouadec, G \& Colomban Ph (2007b) Raman Spectroscopy of Nanostructures and Nanosized Materials. J. Raman Spectrosc. 38, [6], 598-603.

Gouadec, G.; Bellot-Gurlet, L.; Baron, D. \& Colomban, Ph. (2010). Raman mapping for the investigation of nanophased materials, ch. 4, Raman Imaging , A. Zoubir Ed., Springer

Havel M, Baron D and Colomban Ph (2004) Smart Raman/Rayleigh Imaging of Nanosized $\mathrm{SiC}$ Materials Using the Spatial Correlation Model. J. Material Science 39, [20], 61836190.

Havel, M. \& Colomban, Ph. (2006). Smart Raman and Rayleigh Spectroscopy for the Analysis of Nanomaterials, Microscopy and Analysis, 20, [3], 11-14.

Havel, M., Baron, D., Mazerolles L. \& Colomban Ph. (2007). Phonon confinment in SiC nanocrystal. Comparison of the size determination using TEM and Raman spectroscopy, Applied Spectroscopy 61 [8] 855-859. 
Hernandez, M., Genesca, J., Uruchurtu, J., Galliano, F. \& Landolt, D. (2006). Effect of an inhibitive pigment zinc-aluminum-phosphate (ZAP) on the corrosion mechanisms of steel in waterborne coatings, Progr. Organic Coatings, 56, [2-3], 199-206.

Hugot-le-Goff, A. \& Pallotta C. (1985). In situ Raman spectroscopy for the study of iron passivity in relation to solution composition, J. Electrochemical Soc., 132, [11], 28052806.

Joiret, S.; Keddam, M.; Novoa, X.R.; Perez, M.C.; Rangel, C. \& Takenouti, H. (2002). Use of EIS, ring-disk electrode, EQCM and Raman spectroscopy to study the film of oxides formed on iron in $1 \mathrm{M} \mathrm{NaOH}$, Cement $\mathcal{E}$ Concrete Composites, 24, [1], 7-15.

Karr C. Jr, Ed. Infrared and Raman Spectroscopy of Lunar and Terrestrial Minerals, (Academic Press, New York, 1975).

Kashima, K.; Hara, S.; Kishikawa, H. \& Miyuki, H. (2000). Evaluation of protective ability of rust layers on weathering steels by potential measurements, Corrosion Engineering, 49, 25-37.

Hara, S.; Kashima, K.; Kishikawa, H. \& Miyuki, H. (2001). Evaluation on the protective ability by the potential of steel with rust layer related to the composition of the rusr formed on the weathered steel bridge using ternary diagrams, Tetsu to Hagane - J. Iron \& Steel Institute of Japan, 87, [1], 43-48.

Keiser, J.T.; Brown C.W. \& Heidersbach R.H. (1982). Use of Raman spectroscopy in iron corrosion studies, American Laboratory, 14, [4], 17-18.

Kihira, H.; Misawa, T.; Kusunoki, T.; Tanabe, K. \& Saito, T. (1999). How to use the composition ratio index obtained by internal standard quantitative $\mathrm{x}$-ray diffraction to evaluate the state of rust on weathering steel, Corrosion Engineering, 48, 979-987.

Lewis, I.R. \& Edwards, H.G.M. (2001). Handbook of Raman Spectroscopy, From the Research Laboratory to the Process Line, Practical Spectroscopy Series, Marcel Dekker Inc., New-York.

Little, B.J. \& Lee, J.S. (2007). Microbiologically influenced corrosion, John Wiley \& Sons Inc., Hoboken.

Long, D.A., (1977). Raman Spectroscopy. McGraw-Hill, New York.

Lopez, D.A.; Schreiner, W.H.; de Sanchez, S.R. \& Simison, S.N. (2003). The influence of carbon steel microstructure on corrosion layers - An XPS and SEM characterization, Appl. Surface Science, 207, [1-4], 69-85.

Marchebois, H.; Joiret, S.; Savall, C.; Bernard, J. \& Touzain, S. (2002a). Characterization of zinc-rich powder coatings by EIS and Raman spectroscopy, Surface $\mathcal{E}$ Coatings Technology, 157, [2-3], 151-161.

Marchebois, H., Touzain, S., Joiret, S., Bernard, J. \& Savall, C. (2002b). Zinc-rich powder coatings in sea water: influence of conductive pigments, Progr. Organic Coatings, 45, [4], 415-421.

Maslar, J. E.; Hurst, W.S.; Bowers Jr., W.J.; Hendricks, J.H.; Aquino, M.I. \& Levin I. (2001). In situ Raman spectroscopic investigation of chromium surfaces under hydrothermal conditions, Applied Surface Science 180, [1-2], 102-118.

Maslar, J. E.; Hurst, W.S.; Bowers Jr., W.J. \& Hendricks, J.H (2002). In situ Raman spectroscopic investigation of stainless steel hydrothermal corrosion, Corrosion 58, [9], 739-747.

Mazzetti, L. \& Thistlethwaite, P.J. (2002). Raman spectra and thermal transformations of ferrihydrite and schwertmannite, J. Raman Spectroscopy, 33, [2], 104-111. 
Monnier, J.; Bellot-Gurlet, L.; Baron, D.; Neff, D.; Guillot, I. \& Dillmann P. (2010). A methodology for Raman structural quantification imaging and its application to iron indoor atmospheric corrosion products, J. Raman Spectroscopy to be published.

Morke, I.; Stasch A. \& P Wachter (1980). Magnons in Raman scattering of magnetite, Hevetica Physica Acta 53, [4], 582-582.

Nakamoto, K., Infrared \& Raman Spectra of Inorganic and Coordination Compounds: Theory and Application in Inorganic Chemistry, J. Wiley \& Sons, 1997.

Neff, D.; Bellot-Gurlet, L.; Dillmann, P.; Reguer, S. \& Legrand, L. (2006). Raman imaging of ancient rust scales on archaeological iron artefacts for long-term atmospheric corrosion mechanisms study, J. Raman spectroscopy, 37, [10], 1228-1237.

Neff, D.; Dillmann, P.; Bellot-Gurlet, L. \& Beranger, G. (2005). Corrosion of iron archaeological artefacts in soil: characterisation of the corrosion system, Corrosion Science, 47, [2], 515-535.

Nguyen, T.D., Nguyen, T.A., Pham, M.C., Piro, B., Normand, B. \& Takenouti, H. (2004). Mechanism for protection of iron corrosion by an intrinsically electronic conducting polymer, J. Electroanalytical Chemistry, 572, [2], 225-234.

Ohtsuka, T.; Kubo, K. \& Sato N. (1986). Raman spectroscopy in thin corrosion films on iron at 100 to $150^{\circ} \mathrm{C}$ in air, Corrosion-NACE (National Association of Corrosion Engineers), $42,[8], 476-481$.

Pineau, S.; Sabot, R.; Quillet, L.; Jeannin, M.; Caplat, C.; Dupont-Moral, I. \& Refait, P. (2008) : Formation of the Fe(II-III) hydroxysulphate green rust during marine corrosion of steel associated to molecular detection of dissimilatory sulphite-reductase, Corrosion Science, 50, [4], 1099-1111.

Poupard, O.; L'Hostis, V.; Catinaud, S. \& Petre-Lazard I. (2006). Corrosion damage diagnosis of a reinforced concrete beam after 40 years natural exposure in marine environment, Cement and Concrete Research, 36, [3], 504-520.

Refait, Ph.; Memet, J.B.; Bon, C.; Sabot, R. \& Génin J.-M.R. (2003). Formation of the Fe(II)$\mathrm{Fe}(\mathrm{III})$ hydroxysulphate green rust during marine corrosion of steel, Corrosion Science, 45, [4], 833-845.

Refait, Ph.; Reffass, M.: Landoulsi, J.: Sabot, R. \& Jeannin, J. (2007). Role of phosphate species during the formation and transformation of the Fe(II-III) hydroxycarbonate green rust, Colloids and Surfeces A: Physcicochem. E Eng. Aspects, 299, [1-3], 29-37.

Remazeilles, C.; Saheb, M.; Neff, D.; Guilminot, E.; Tran, K.; Bourdoiseau, J.-A.; Sabot, R.; Jeannin, M.; Matthiesen, H.; Dillman, Ph. \& Refait, Ph. (2010). Microbiologically influenced corrosion of archaeological artefacts : characterization of iron (II) sulfides by Raman spectroscopy, J. Raman Spectroscopy, DOI: 10.1002/jrs.2717.

Saheb, M.; Neff, D.; Dillmann, P.; Matthisen, H. \& Foy, E. (2009). Long-term corrosion behaviour of low-carbon steel in anoxic environments - Characterisation of archaeological artefacts, J. Nuclear Materials, 379, [1-3], 118-123.

Savoye, S.; Legrand, L.; Sagon, G.; Lecomte, S.; Chausse, A.; Messina, R. \& Toulhoat, P. (2001). Experimental investigations on iron corrosion products formed in bicarbonate/carbonate-containing solutions at $90^{\circ} \mathrm{C}$, Corrosion Science, 43, [11], 2049-2064.

Simard, S.; Odziemkowski, M.; Irish, D.E.; Brossard, L. \& Ménard, H (2001). In situ microRaman spectroscopy to investigate pitting corrosion product of 1024 mild steel in 
phosphate and bicarbonate solutions containing chloride and sulphate ions? J. Appl. Electrochemistry, 31, [8], 913-920.

Thibeau, R.J.; Brown, C.W. \& Heidersbach, R.H. (1978). Raman spectra of possible corrosion products of iron, Appl. Spectroscopy 32, [6], 532-535.

Tomandl, A.; Wolpers, M. \& Ogle, K. (2004). The alkaline stability of phosphate coatings II: in situ Raman spectroscopy, Corrosion Science, 46, [4], 997-1011.

Turrell, G. (1996). Chap 4: Raman Imaging. in: Turrell G and Corset J (eds) Raman Microscopy. Developments and Applications. Academic Press, London.

Yadav, A.P.; Nishikata, A. \& Tsuru, T. (2004). Degradation mechanism of galvanized steel in wet-dry cyclic environment containing chloride ions, Corrosion Science, 46, [2], 361-376.

Videla, H.A. \& Characklis, W.G. (1992). Biofouling and microbially influenced corrosion, Int. Biodeterioration Biodegradation, 29, [3-4], 195-212.

Vucinic-Vasic, M.; Antic, B.; Kremenovic, A.; Nikolic A.; Stoiljkovic, M.; Bibic N.; Spasojevic, V. \& Colomban Ph. (2006). Zn,Ni ferrite/NiO nanocomposite powder obtained from acetylacetanoto complexes, Nanotechnology 17, [19], 4877-4884.

Widjaja, E.; Lim, C.H.; Lim, Q.; Mashadi, A.B. \& Garland M. (2010). Pure component Raman spectral reconstruction for glazed and unglazed Yuan, Ming and Qing shards: a combined Raman microscopy and BTEM study, J. Raman Spectrosc. DOI: 10.1002/jrs.2721.

Wu, J. \& Colomban Ph. (1997). Raman spectroscopy study on the stress distribution in the continuous fibre reinforced ceramic matrix composites. J. Raman Spectrosc. 28 523529.

Yamashita, M.; Miyuki H.; Matsuda Y.; Nagano H. \& Misawa T. (1994). The long-term growth of the protective rust layer formed on weathering steel by atmospheric corrosion during a quarter of century, Corrosion Science 36, [2], 283-299.

Zuo, J.; Xu, C.; Hou, B.; Wang, C.; Xie, Y. \& Quian Y. (1996). Raman spectra of Nanophase $\mathrm{Cr}_{2} \mathrm{O}_{3}$, J. Raman Spectroscopy, 27, 921-923. 


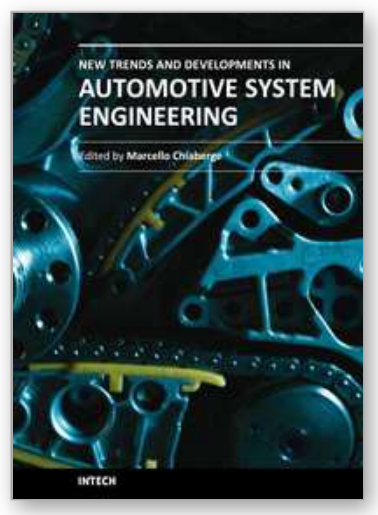

\author{
New Trends and Developments in Automotive System Engineering \\ Edited by Prof. Marcello Chiaberge
}

ISBN 978-953-307-517-4

Hard cover, 664 pages

Publisher InTech

Published online 08, January, 2011

Published in print edition January, 2011

In the last few years the automobile design process is required to become more responsible and responsibly related to environmental needs. Basing the automotive design not only on the appearance, the visual appearance of the vehicle needs to be thought together and deeply integrated with the â€œpowerâ€ developed by the engine. The purpose of this book is to try to present the new technologies development scenario, and not to give any indication about the direction that should be given to the research in this complex and multi-disciplinary challenging field.

\title{
How to reference
}

In order to correctly reference this scholarly work, feel free to copy and paste the following:

Philippe Colomban (2011). Potential and Drawbacks of Raman (Micro)spectrometry for the Understanding of Iron and Steel Corrosion, New Trends and Developments in Automotive System Engineering, Prof. Marcello Chiaberge (Ed.), ISBN: 978-953-307-517-4, InTech, Available from: http://www.intechopen.com/books/newtrends-and-developments-in-automotive-system-engineering/potential-and-drawbacks-of-raman-microspectrometry-for-the-understanding-of-iron-and-steel-corrosio

\section{INTECH}

open science | open minds

\section{InTech Europe}

University Campus STeP Ri

Slavka Krautzeka 83/A

51000 Rijeka, Croatia

Phone: +385 (51) 770447

Fax: +385 (51) 686166

www.intechopen.com

\section{InTech China}

Unit 405, Office Block, Hotel Equatorial Shanghai

No.65, Yan An Road (West), Shanghai, 200040, China

中国上海市延安西路65号上海国际贵都大饭店办公楼405单元

Phone: +86-21-62489820

Fax: +86-21-62489821 
(C) 2011 The Author(s). Licensee IntechOpen. This chapter is distributed under the terms of the Creative Commons Attribution-NonCommercialShareAlike-3.0 License, which permits use, distribution and reproduction for non-commercial purposes, provided the original is properly cited and derivative works building on this content are distributed under the same license. 